\title{
Low-grade fibromyxoid sarcoma incidentally discovered as an asymptomatic mediastinal mass: a case report and review of the literature
}

\author{
Mir Ibrahim Sajid ${ }^{1}$, Sidra Arshad ${ }^{2}$, Jamshid Abdul-Ghafar ${ }^{3 *}$ (D), Saulat Hasnain Fatimi ${ }^{4}$ and Nasir Ud Din ${ }^{2}$
}

\begin{abstract}
Background: Low-grade fibromyxoid sarcoma (LGFMS) is a rare tumor characterized by bland histological features and aggressive clinical course. The most common anatomic locations of occurrence are the lower extremities, thorax, inguinal area, and upper limbs. Primary mediastinal sarcomas are even rarer. To the best of our knowledge, only seven cases of primary mediastinal LGFMS have been reported in the literature. Here, we report a case of primary mediastinal LGFMS.

Case presentation: A 26-year-old Pakistani man presented with fever and vomiting for the past 2 months. On a routine chest $x$-ray, a mediastinal mass was incidentally found. Computed tomography (CT) scan showed a large circumscribed lobulated soft tissue density mass lesion in an anterior mediastinum. Grossly, the resected mass measured $17.0 \times 12.0 \times 11.0 \mathrm{~cm}$. The cut surface was gray white with a whorled-like appearance and foci of calcification and cystic changes. Histologically, a spindle cell lesion was seen with alternating myxoid and hyalinized areas. The shaped cells were arranged in bundles. Immunohistochemical staining showed positive reactivity patterns with MUC4 and focally for epithelial membrane antigen (EMA). The diagnosis was confirmed as LGFMS. The patient is free of symptoms and recurrence 22 months after the surgery.
\end{abstract}

Conclusion: In conclusion, we report a rare case of primary mediastinal LGFMS in a young male patient that was discovered incidentally. Our patient is on regular follow-up to look for evidence of recurrence as these tumors are prone to recurrences.

Keywords: Low-grade fibromyxoid sarcoma, Mediastinum, Aggressive behavior

\section{Introduction}

Low-grade fibromyxoid sarcoma (LGFMS) is a rare tumor with generic histologic characteristics and intense clinical progression. This tumor is found predominately in the extremities, both upper and lower, inguinal region, and thorax [1]. On histological examination, this tumor is found to consist of alternating fibrous and myxoid areas, arranged in a spiral fashion with fibroblast spindle cells

*Correspondence: Jamshid.jalal@fmic.org.af

3 Department of Pathology and Clinical Laboratory, French Medical

Institute for Mothers and Children (FMIC), Kabul, Afghanistan

Full list of author information is available at the end of the article that appear benign. Primary mediastinal sarcomas are rarer than ever. To the best of the authors' knowledge and the literature search performed, only seven cases of primary mediastinal LGFMS have been reported [2-7], and this is an additional rare case of primary mediastinal LGFMS with typical histological findings, which was confirmed by immunohistochemical (IHC) stains [8].

Since this was a retrospective observational study and did not involve actual patients or patient's images, ethical approval was not sought for this study.

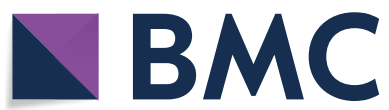

(c) The Author(s) 2021. Open Access This article is licensed under a Creative Commons Attribution 4.0 International License, which permits use, sharing, adaptation, distribution and reproduction in any medium or format, as long as you give appropriate credit to the original author(s) and the source, provide a link to the Creative Commons licence, and indicate if changes were made. The images or other third party material in this article are included in the article's Creative Commons licence, unless indicated otherwise in a credit line to the material. If material is not included in the article's Creative Commons licence and your intended use is not permitted by statutory regulation or exceeds the permitted use, you will need to obtain permission directly from the copyright holder. To view a copy of this licence, visit http://creativecommons.org/licenses/by/4.0/. The Creative Commons Public Domain Dedication waiver (http://creativeco mmons.org/publicdomain/zero/1.0/) applies to the data made available in this article, unless otherwise stated in a credit line to the data. 


\section{Case presentation}

A 26-year-old Pakistani man presented with fever and vomiting (non-bilious and non-bloody). He had been under treatment in another hospital for the past 2 months. Due to progressive worsening of symptoms, he was kept as an inpatient with a working diagnosis of acute hepatitis $\mathrm{A}$ and jaundice and was managed accordingly. A mediastinal mass was incidentally found during a routine chest X-ray (Fig. 1a, b). A computed tomography (CT) scan was then ordered to characterize the lesion. The CT scan showed a large circumscribed soft tissue density lesion in the anterior mediastinum, extending laterally in the right hemithorax abutting the anterior and right lateral chest wall without evidence of infiltration (Fig. 2a, b). Superiorly, it was extending into the root of the neck, abutting the posterior cortex of the medial end and compressing the superior vena cava, displacing the ascending and arch of the aorta as well as its major branches, trachea, and esophagus toward the left side. Multiple foci of coarse calcifications were also noted within the lesion. The lesion measured $16.9 \times 12.8 \times 11.0 \mathrm{~cm}$. The described

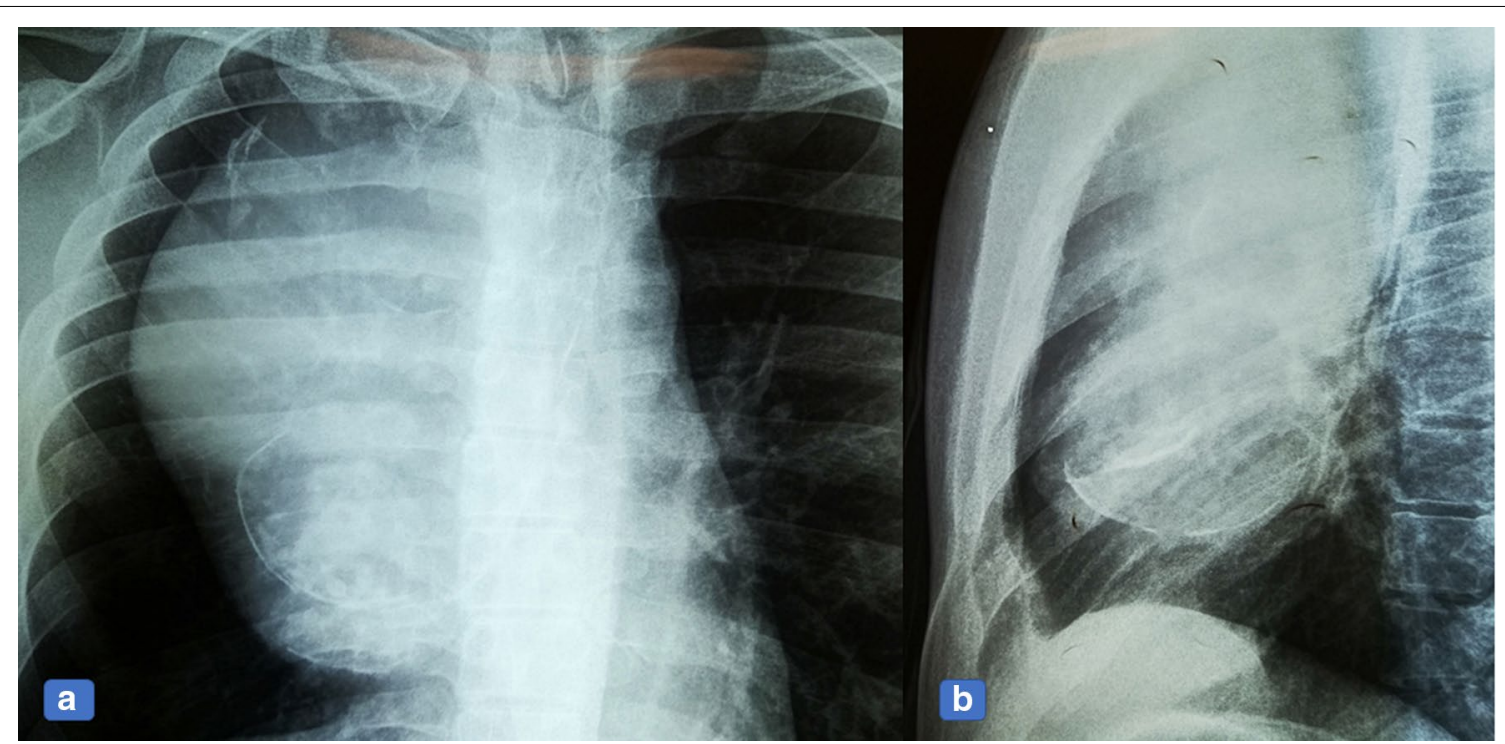

Fig. 1 a Chest x-ray, Anterior Posterior (AP) view, showing a large, lobulated, soft tissue density mass with internal calcification. It forms an obtuse angle causing superior mediastinal widening, more on the right side. $\mathbf{b}$ Lateral chest $\mathrm{x}$-ray shows obliteration of the retrosternal space.

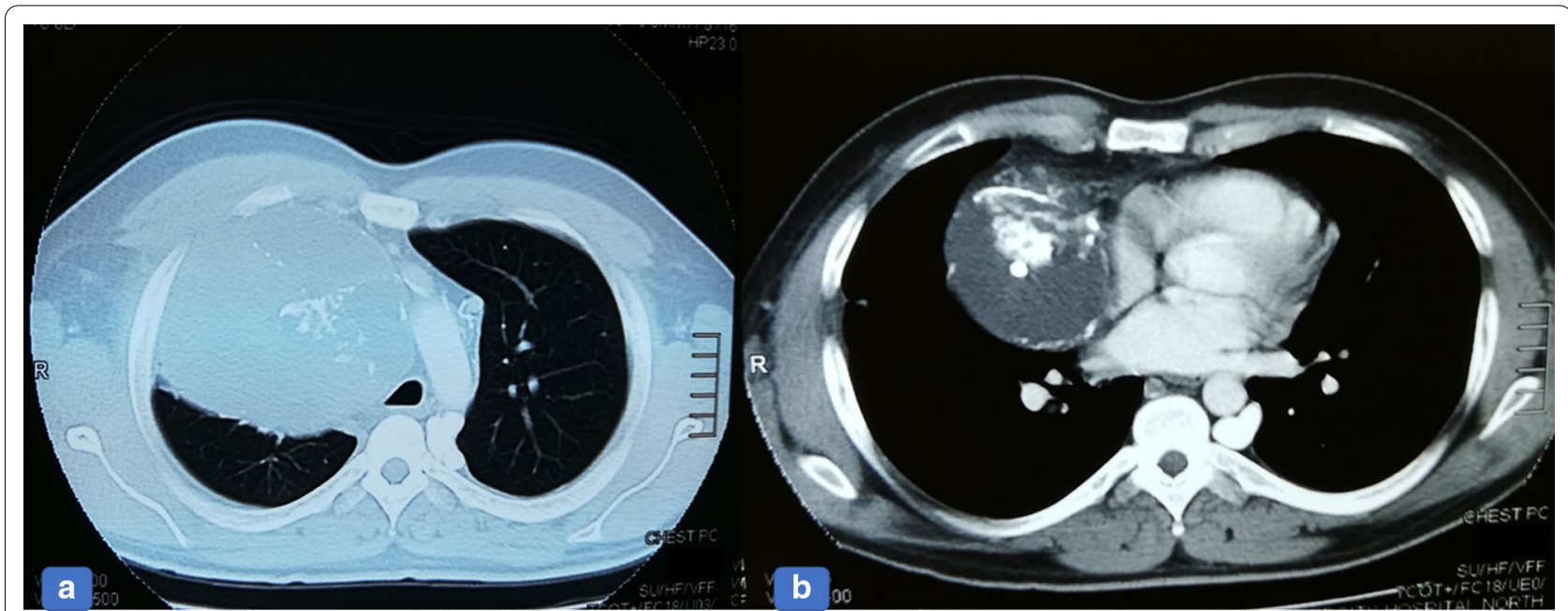

Fig. 2 a, b Axial images of the chest-lung computed tomography and mediastinal window show well-defined rounded low attenuation mass with internal coarse calcification. 
imaging features suggested the possibilities of a germ cell tumor or hydatid cyst. For surgical resection of the mass, the patient was referred to our hospital. The patient was briefed about the procedure and was taken to the operating theatre for right thoracotomy and tumor resection with an American Society of Anesthesiologists (ASA) score of II. Intraoperatively, a $20.3 \times$ $12.7 \mathrm{~cm}$ solid mass filled with green cystic fluid was visualized extending to the right hemothorax. It was not adherent to the lung but had definite adhesions with the hilar structures.

Grossly, the resected mass was encapsulated and measured $17.0 \times 12.0 \times 11.0 \mathrm{~cm}$. The cut surface was gray white with a whorled-like appearance and foci of calcification and cystic areas (Fig. 3). Histologically, a spindle cell lesion is seen with alternating myxoid and hyalinized areas. The shaped cells were arranged in bundles. In areas, myxoid hypocellular areas were identified with few intervening dilated blood vessels and dense collagen bundles (Fig. 4a, b). Multiple foci of calcifications were visualized at the periphery with collagen rosettes. A few areas also showed a sprinkling of inflammatory cells, predominantly plasma cells. IHC staining was performed, which showed positive reactivity patterns with MUC4 and focally for epithelial membrane antigen (EMA) (Fig. 4c, d). CD34, anti-smooth muscle actin (ASMA), desmin, and $\mathrm{S} 100$ protein stains were negative. The diagnosis was confirmed as LGFMS.

Postoperatively, the patient was kept nil per oral for 6 hours and started on intravenous analgesics and antibiotics. His chest $\mathrm{x}$-ray showed no residual mass, consolidation, pneumothorax, or pleural effusion. He was sent home in a stable condition on the 4th day of surgery and followed in the clinic for 2 months. The patient is free of symptoms and recurrence 22 months after surgery.

\section{Discussion}

In 1987, Evans first recognized LGFMS as a unique entity seen in young and middle-aged adults, which was initially identified as a slow-growing, asymptomatic tumor of the soft tissue with a deceivingly mild histology but with a higher risk of recurrence and metastasis [9].

The tumor mainly involves the deep soft tissue of the lower extremities, especially the thigh, limb girdle, and trunk. Mediastinal occurrence is very rare (Table 1). In 1999, Takanami et al. reported the first case of mediastinal LGFMS in a 35-year-old male, which was primarily misdiagnosed as neurofibroma [2]. After 9 years, it recurred and was then correctly diagnosed as LGFMS. The age range of all patients with reported mediastinal

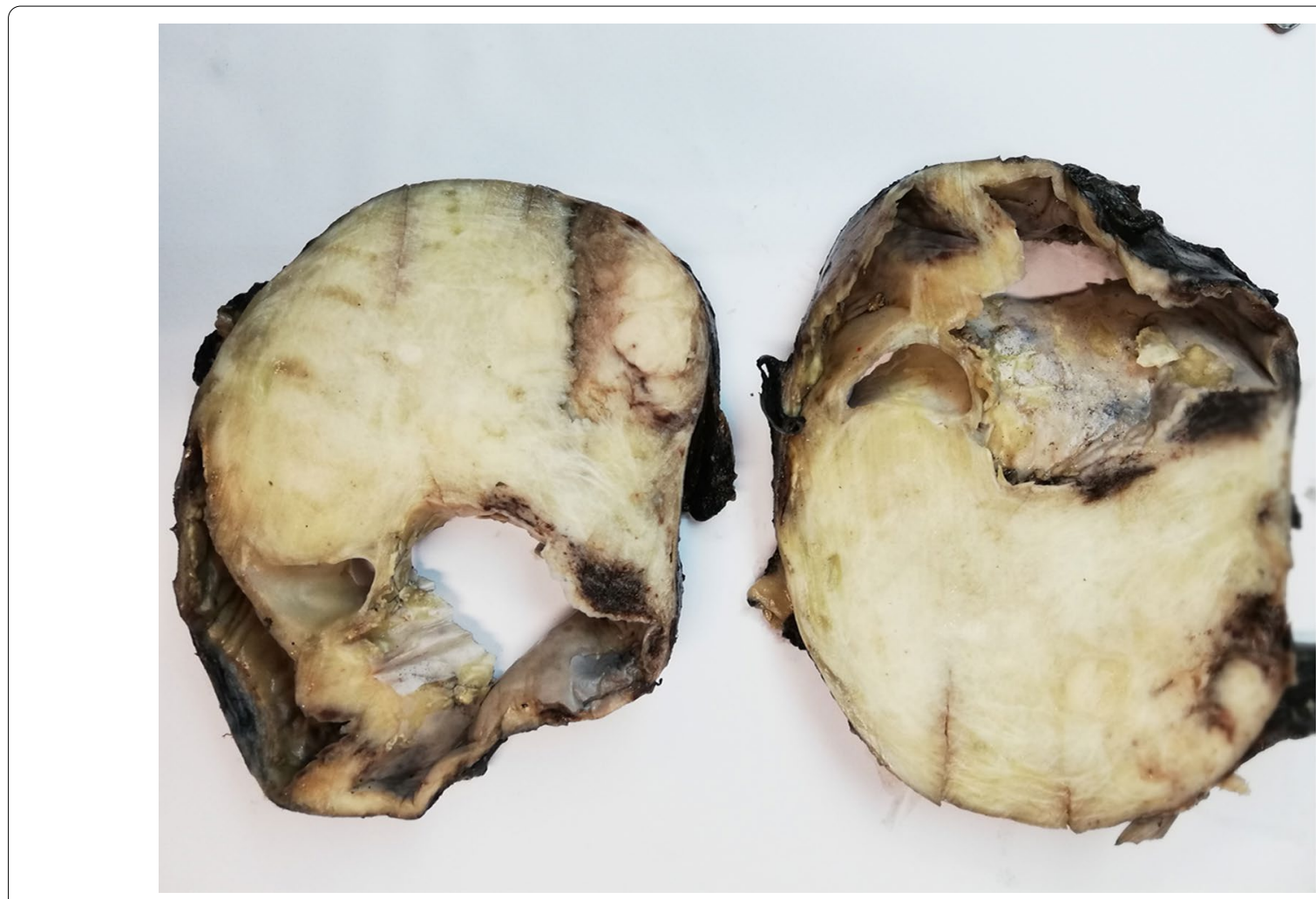

Fig. 3 Gross examination. Cut surface shows a gray-white, firm, solid tumor with cystic areas 

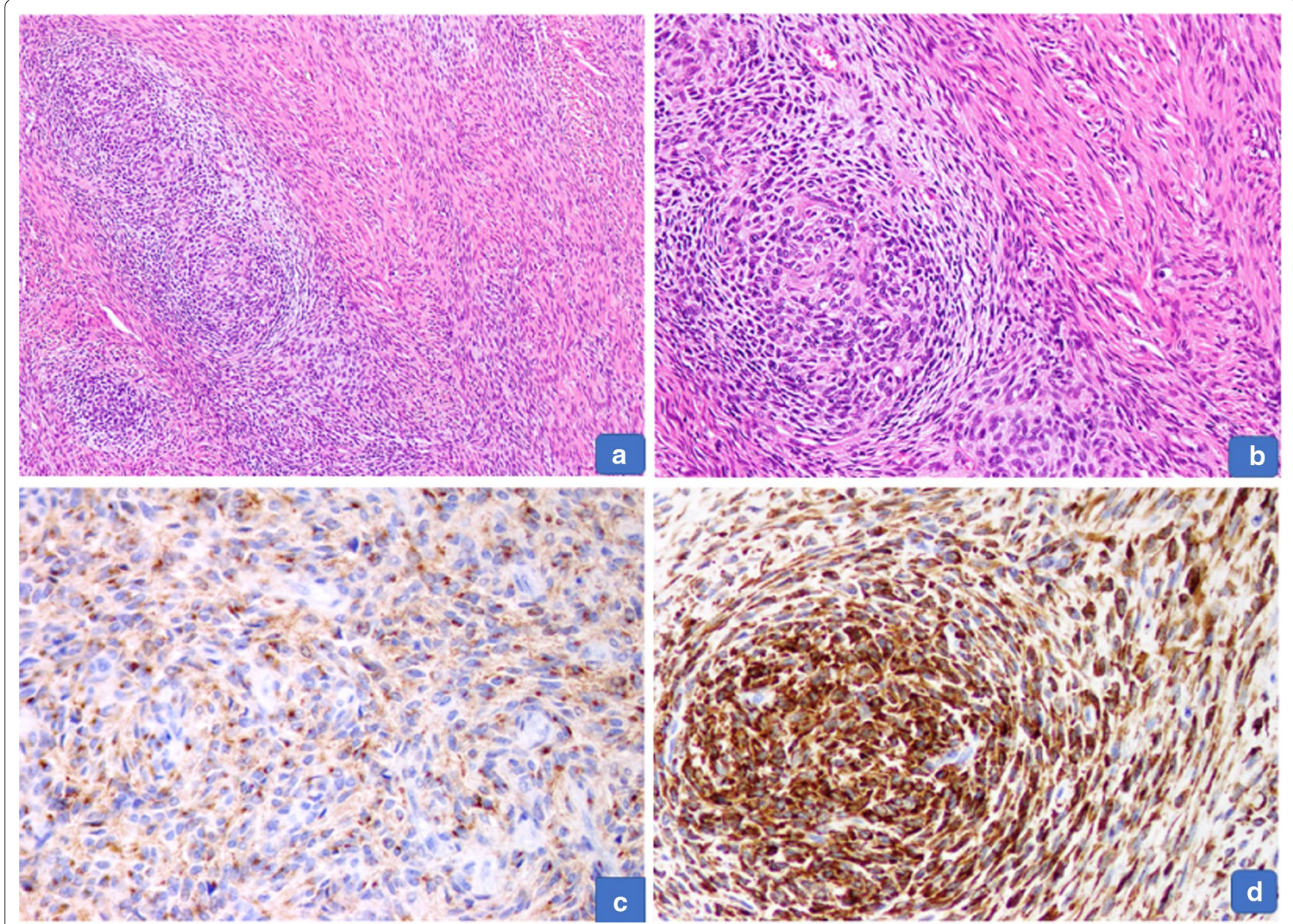

Fig. 4 a, b Low and intermediate power shows a tumor with alternating cellular myxoid and fewer cellular collagenized areas. c EMA positivity in tumor cells. d Diffuse strong MUC 4 positivity in tumor cell

LGMS ranged from 19 to 50 years (mean 35.1 years; median 35 years). Four patients were male, and three patients were female. The tumor size varied between 8 and $23.5 \mathrm{~cm}$ (mean 13.3; median $12 \mathrm{~cm}$ ). Histologically, myxoid areas alternating with collagenized areas composed of spindle cells were observed in four cases, and giant collagen rosettes were also present in three cases. The follow-up period was of variable duration for these cases. Recurrence after 7 and 9 years was observed in two cases. Long-term follow-up is therefore recommended because of the risk of late recurrence and metastasis.

The histological differential diagnoses of LGFMS include solitary fibrous tumor, low-grade peripheral sheath tumor, neurofibroma, and desmoid fibromatosis. Solitary fibrous tumor with dilated hemangiopericytoma-like vessels and variable stromal collagen exhibits a patternless growth pattern. Tumor cells have homogeneous to ovoid nuclei and an indistinct cytoplasm. In most cases, CD34 is positive, and positivity to STAT6 is diagnostic [10]. Aggressive low-grade peripheral sheath tumor cells show a curly tapered nucleus and cytological atypia and are positive for S100 and SOX10 and negative for MUC4; they show loss of expression for H3K27me. Neurofibroma shows haphazard proliferation of elongated spindle cells that exhibit cytoplasmic eosinophilic processes present in a collagenized or myxoid stroma for stromal mast cells. Tumor cells are positive for S100, SOX10, and CD34 and negative for MUC4. Desmoid fibromatosis shows long, sweeping fascicles with pinpoint nuclei of fibro-/myofibroblastic spindle cells. This tumor is positive for ASMA and beta-catenin and negative for MUC4. Typical histological findings of LGFMS and a positive reaction for MUC4 help to establish a correct diagnosis. Clinical behavior of mediastinal LGFMS seems to be comparable to the LGFMS of extremities.

Approximately $20-25 \%$ of all sarcomas show some forms of chromosomal translocations. The majority of LGFMSs have a recurrent balanced translocation between chromosomes 7 and 16, involving the long arm (q) of chromosomes 32-34 and the short arms (p) 11, 


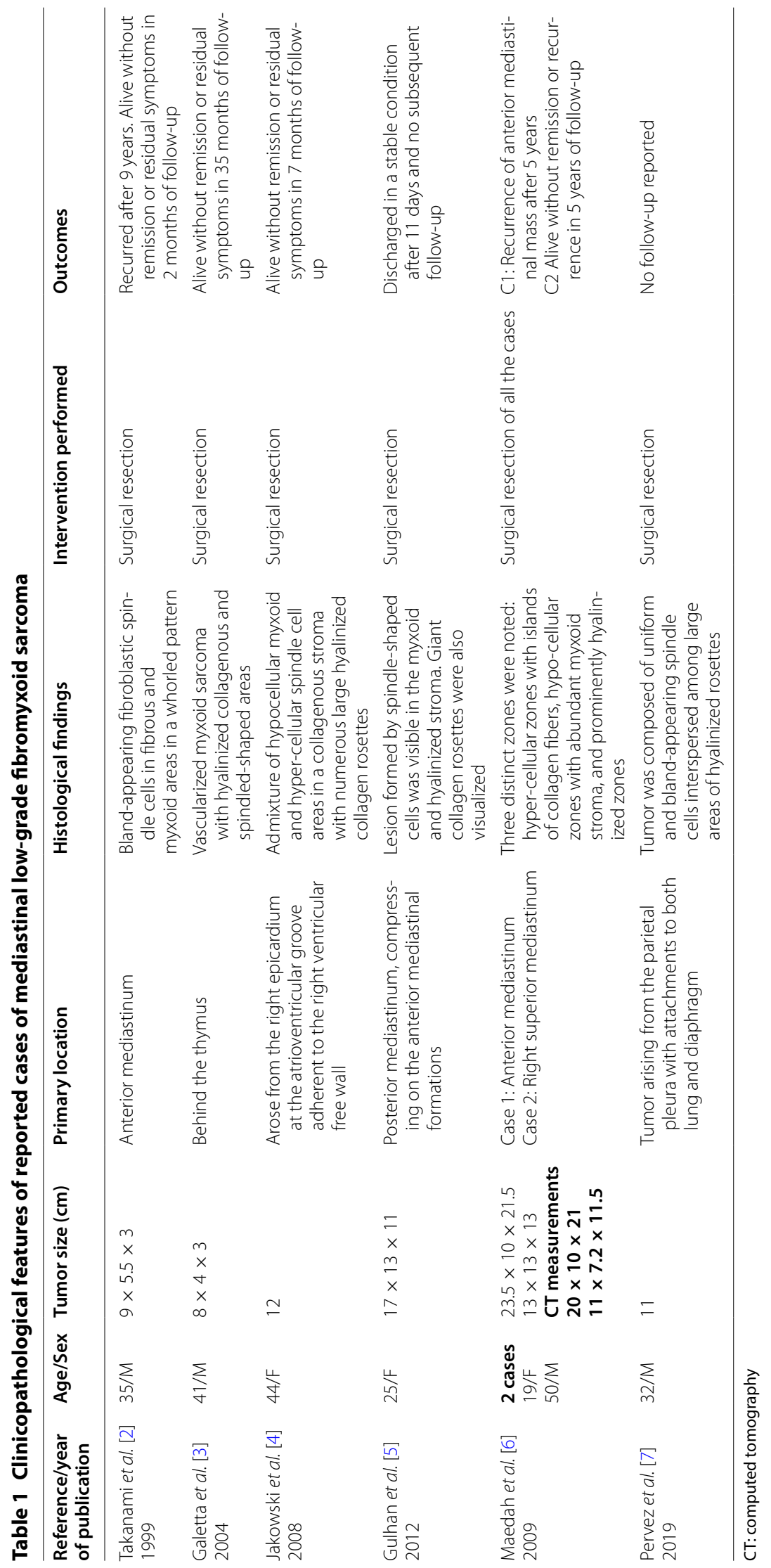


which results in the union of 'Fused in Sarcoma' RNA binding protein' (FUS) and the CREB3L2 gene [Complex 1]. Translocation of 'FUS-CREB3L1' fusion gene is reported in about $5 \%$ of the LGFMS cases. The genes CREB3L2 and CREB3L1 play a critical role in codifying transcription factors and contributing to the pathogenesis of the disease. In a study of 14 patients diagnosed with LGFMS, Cesne et al. found no association between Complex 1 and the metastatic or recurrent potential of the tumor [11-13].

It is possible to use combined radiotherapy and chemotherapy for locally advanced unrespectable tumors. As with other soft tissue sarcomas, pre- or postoperative radiotherapy with often infiltrative growth patterns can be considered to improve local cancer spread, particularly in the extremities. Some centers use 'isolated limb perfusion' (ILP) to salvage limbs during surgery and avoid radiotherapy in a select few patients. Among other localized treatments are cryoablation and radiofrequency ablation (RFA) and cryoablation to treat cancers with more than metastatic lesions $[14,15]$.

\section{Conclusion}

In conclusion, we report a rare case of primary mediastinal LGFMS that was incidentally discovered in a young male patient. Our patient is regularly looking for evidence of recurrence as these tumors are prone to recurrence. This aggressive sarcoma with a benign appearance should always be present in the differential diagnosis of all benign-looking neoplasms of the spindle cells.

\section{Abbreviations \\ LGFMC: Low-grade fibromyxoid sarcoma; IHC: Immunohistochemical; CT: Computed tomography; EMA: Epithelial membrane antigen; ASA: American Society of Anesthesiologists; ASMA: Anti-smooth muscle actin; ILP: Isolated limb perfusion; RFA: Radiofrequency ablation.}

\section{Acknowledgements}

Not applicable.

\section{Authors' contributions}

NUD and SA performed the histological and immunohistochemical evaluation; MIS was involved in the literature review and drafted the manuscript; SHF performed the surgery on the patient and helped to collect clinical and follow-up data; JA-G participated with the corresponding, reviewing, and final revision of the drafted manuscript and edition as per journal policy, and submission of the article. All authors read and approved the final manuscript.

\section{Funding}

No financial support was provided for this study.

\section{Availability of data and materials}

Data and materials used in this work are available from the corresponding author on reasonable request.

\section{Ethics approval and consent to participate}

All procedures performed on patient tumor samples in this study were in accordance with the ethical standards of the Institute Ethics Committee and with the 1964 Helsinki Declaration and its later amendments or comparable ethical standards. Since this was a retrospective observational study and did not involve actual patients or patients' images, ethical approval was not sought for this study.

\section{Consent for publication}

Written informed consent was obtained from the patient for publication of this case report and any accompanying images. A copy of the written consent is available for review by the Editor-in-Chief of this journal.

\section{Competing interest}

It is declared that all authors have no conflict of interest.

\section{Author details}

${ }^{1}$ Medical College, Aga Khan University, Karachi, Pakistan. ${ }^{2}$ Department of Pathology and Laboratory Medicine, Aga Khan University Hospital, Karachi, Pakistan. ${ }^{3}$ Department of Pathology and Clinical Laboratory, French Medical Institute for Mothers and Children (FMIC), Kabul, Afghanistan. ${ }^{4}$ Section of Cardiothoracic Surgery, Department of Surgery, Aga Khan University Hospital, Karachi, Pakistan.

Received: 24 June 2020 Accepted: 27 November 2020

Published online: 02 February 2021

\section{References}

1. Tang Z, Zhou ZH, Lv CT, Qin LY, Wang Y, Tian G, Luo XL, Zhu Q, Xu XG. Low-grade fibromyxoid sarcoma: clinical study and case report. J Oral Maxillofac Surg. 2010;68(4):873-84.

2. Takanami I, Takeuchi K, Naruke M. Low-grade fibromyxoid sarcoma arising in the mediastinum. JThorac Cardiovasc. 1999;1 18(5):970-1.

3. Galetta D, Cesario A, Margaritora S, Granone P. Primary mediastinal hyalinizing spindle cell tumor with giant rosettes. Ann Thorac Surg. 2004;77(6):2206-9.

4. Jakowski JD, Wakely PE Jr. Primary intrathoracic low-grade fibromyxoid sarcoma. Hum Pathol. 2008;39(4):623-8.

5. Gülhan SŞ. Low-grade fibromyxoid sarcoma in the mediastinum: a case report. Turk Gogus Kalp Dama. 2012;20(2):374-6.

6. Maeda E, Ohta S, Watadani T, Goto A, Nakajima A, Ohtomo K. Imaging findings of thoracic low-grade fibromyxoid sarcoma: report of three cases. Jpn J Radiol. 2009;27(9):375.

7. Perez D, El-Zammar O, Naous R. Low-grade fibromyxoid sarcoma: a rare case in an unusual location. Am J Clin Pathol. 2019;152(Supplement_1):S54.

8. Shimizu Y, Tsuchiya K, Fujisawa H. Intracranial low-grade fibromyxoid sarcoma: findings on electron microscopy and histologic analysis. World Neurosurg. 2020;135:301-5.

9. Evans HL. Low-grade fibromyxoid sarcoma: a report of two metastasizing neoplasms having a deceptively benign appearance. Am J Clin Pathol. 1987:88(5):615-9.

10. Doyle LA, Vivero M, Fletcher CD, Mertens F, Hornick JL. Nuclear expression of STAT6 distinguishes solitary fibrous tumor from histologic mimics. Mod Pathol. 2014;27(3):390-5. https://doi.org/10.1038/modpathol.2013.164.

11. Maretty-Nielsen K, Baerentzen S, Keller J, Dyrop HB, Safwat A. Low-grade fibromyxoid sarcoma: incidence, treatment strategy of metastases, and clinical significance of the FUS gene. Sarcoma. 2013. https://doi. org/10.1155/2013/256280.

12. Le CA, Cresta S, Maki RG, Blay JY, Verweij J, Poveda A, Casali PG, Balaña C, Schöffski P, Grosso F, Lardelli P, Nieto A, Alfaro V, Demetri GD. A retrospective analysis of antitumour activity with trabectedin in translocationrelated sarcomas. Eur J Cancer. 2012;48(16):3036-44.

13. Chamberlain F, Engelmann B, Al-Muderis O, Messiou C, Thway K, Miah A, Zaidi S, Constantinidou A, Benson C, Gennatas S, Jones RL. Low-grade fibromyxoid sarcoma: treatment outcomes and efficacy of chemotherapy. In Vivo. 2020;34(1):239-45.

14. Provenzano S, Raimondi A, Bertulli RM, Colia V, Renne SL, Collini P, Dagrada G, Callegaro D, Fiore M, Greco FG, Casali PG. Response to isolated limb perfusion and chemotherapy with epirubicin plus ifosfamide in a metastatic malignant ossifying fibromyxoid tumor. Clin Sarcoma Res. 2017;7:20. 
15. Jakob J, Smith HG, Wilkinson MJ, Pencavel T, Miah AB, Thomas JM, Tunn P-U, Pilz LR, Strauss DC, Hohenberger P, Hayes AJ. Regional chemotherapy by isolated limb perfusion prior to surgery compared with surgery and post-operative radiotherapy for primary, locally advanced extremity sarcoma: a comparison of matched cohorts. Clin Sarcoma Res. 2018:8:12.

\section{Publisher's note}

Springer Nature remains neutral with regard to jurisdictional claims in published maps and institutional affiliations.
Ready to submit your research? Choose BMC and benefit from:

- fast, convenient online submission

- thorough peer review by experienced researchers in your field

- rapid publication on acceptance

- support for research data, including large and complex data types

- gold Open Access which fosters wider collaboration and increased citations

- maximum visibility for your research: over $100 \mathrm{M}$ website views per year

At BMC, research is always in progress.

Learn more biomedcentral.com/submissions 